\title{
“NO OLVIDES, NO OLVIDES": LA CONSTRUCCIÓN DE LA MEMORIA EN EL OTRO SUEÑO AMERICANO DE ENRIQUE ARROYO (2004)
}

\author{
POR \\ Maricruz Castro Ricalde \\ Tecnológico de Monterrey, campus Toluca
}

En los momentos finales del premiado cortometraje de Enrique Arroyo, El otro sueño americano (2004), ${ }^{1}$ el gringo Timoteo le dice al corrupto policía Genaro: "No olvides, no olvides", en un enunciado que simultáneamente funciona como una orden y una recomendación. Es significativa esta apelación en un filme que aborda de manera frontal los asesinatos de las mujeres en la frontera entre México y Estados Unidos y sugiere algunas de las causas de su desaparición, el robo de menores de edad y la trata de personas. Mientras que el llamado de Timoteo se refiere a la solicitud de unos riñones infantiles, el espectador registra también la invocación siempre presente en los giros culturales de la memoria social cultivada en México en poco más de cuatro décadas.

"Dos de octubre, no se olvida" es un recordatorio que año con año reaparece insistentemente en los días previos y posteriores a la fecha. La frase que se grita, se pinta en las paredes, se publica en los impresos y se menciona en todo tipo de discursos revela la dimensión del trauma implicado en la masacre de Tlatelolco de 1968; su formulación, las implicaciones históricas y políticas que trajo consigo. La memoria de los abusos públicos del poder actuó en el sentido de interrupción analizado por Walter Benjamin, según puede constatarse en las fracturas registradas dentro del sistema político mexicano a raíz del 68. El enunciado del personaje ("no olvides, no olvides") es el punto de partida de las siguientes líneas que aspiran a discutir prioritariamente la cuestión de la forma narrativa cinematográfica, cuando ésta imbrica estrategias tradicionales del género documental en un texto que oculta expresamente su esencia ficcional. El cortometraje de Enrique Arroyo me permitirá llegar a algunas conclusiones relacionadas con la naturaleza de los relatos hegemónicos y las versiones que ponen a circular los discursos artísticos; en este caso, las narraciones cinematográficas vinculadas con los feminicidios de Ciudad

1 Es realmente numerosa la cantidad de reconocimientos que ha recibido. Destaco unos cuantos: Grand Prix, Festival de Cine de Clermont-Ferrand; Mickeldi de Oro, Festival de Cine de Bilbao; Coral de Oro, Festival de Cine de la Habana; Prix Signis, Festival de Cine Latino de Toulouse; Danzante de Oro Iberoamericano, Festival de Cine de Huesca; Grand Prix , Festival Internacional de Cortometrajes de Upsala. 
Juárez. El "otro sueño" planteado en el título del filme delataría ese ir a contrapelo de la historia al que aspiraba Benjamin, al construir un texto cinematográfico carente de esperanza y sin deseo de avizorar salida alguna al caos. Sólo la delación final de una cámara que está filmando todo lo que vemos apuntaría hacia la ética del público en quien recaería la responsabilidad sobre el futuro y la historia posible. Mi intención, pues, se encamina a reiterar cómo las obras artísticas formarían parte de un esfuerzo colectivo para construir los relatos de memoria que sustentan el orden ético de las sociedades.

\section{REFERENCIALIDAD Y CONTEXTO}

En el filme de Enrique Arroyo, la tortura y el asesinato de mujeres son tanto una vertiente más de crímenes en los que intervienen distintos actores sociales de ambos lados de la frontera como una profecía. Estrenado en el 2004, este filme no ha perdido su vigencia no obstante la alta dosis referencial que lo sustenta, lo cual permite proponerlo como una construcción textual que forma parte de un entramado estético y, por lo tanto, político y social. Los recursos formales que solventan a El otro sueño americano lo plantean como un signo complejo sobre el presente, lo que imposibilita su abordaje directo desde los múltiples ejes que constituyen los estudios sobre la memoria: "pasado como un tiempo anterior, pasado como estructura de la verdad, pasado como experiencia traumática" (Valdata 173).

Con una duración de diez minutos, la obra de Arroyo se compone de siete tomas suturadas de tal manera que el montaje es imperceptible para la audiencia. Ésta la aprecia como una sucesión de hechos ofrecidos de manera casi ininterrumpida y dados los mecanismos de su presentación, como si fuera un segmento filmado "en vivo", como una cámara escondida y en forma parecida al espíritu que anima un programa de la denominada tele-realidad o reality-show. Este recurso alienta el horror plasmado en lo que se cuenta debido a que reitera el aspecto imperfectivo inherente al espectáculo cinematográfico. ${ }^{2}$

Elotro sueño americano muestra a Sandra, una joven prostituta, que ha sido detenida en posesión de una pequeña dosis de cocaína. Genaro, el policía judicial que la lleva en su patrulla, le insinúa la posibilidad de liberarla a cambio de favores sexuales. La invita a consumir de su droga ("te voy a invitar a una rayita, pero de la mía"), de una calidad muy superior a la de la chica, y a practicarle sexo oral para luego propinarle una paliza, fruto de su indignación porque Sandra, quien también dice llamarse Ingrid, ha escupido su semen. En sus recriminaciones, el agente del orden da a conocer sus prejuicios ("si fuera gringo, seguro que te los tragabas, ¿verdad, puerca?”) y su desinformación (“iyo

La audiencia aprehende el texto cinematográfico como si estuviera ocurriendo "en directo", "en proceso de realización". Esta característica es el "aspecto" y se refiere a cómo se plantean las acciones, terminadas o no (Gaudreault 110-111).

Revista Iberoamericana, Vol. LXXXI, Núm. 251, Abril-Junio 2015, 569-581 ISSN 0034-9631 (Impreso) 
no tengo infecciones, culera!"). En venganza, la lleva con un tratante de personas, mientras que en el trayecto le cuenta lo que le espera. Él ha visto cómo torturan y matan a las mujeres: "Primero te van a coger entre muchos hasta que te sangre la panochita [...] te apagan cigarros en la verijas. Ya cuando se hartan de ti te matan a patadas como perro. Muerta te siguen cogiendo. [...] A una le metieron un tubo por el culo hasta que le perforaron los pulmones [...] Todavía estaba viva cuando empezaron. Hay días en que todavía escucho sus gritos" (5:20/6:22). Los llantos de la joven no conmueven a Genaro quien se la entrega a Timoteo, un ex soldado estadounidense, con quien tiene tratos el jefe del policía y a quien le pide no seguir tirando cuerpos femeninos en las vías del tren. El gringo promete tener relaciones sexuales con Sandra antes de que lleguen unos "pinches locos" de Texas que la quieren para "descarnarla", deshollarla viva. Antes de despedirse, le solicita unos riñones "chiquitos". El cortometraje finaliza cuando el judicial apaga la cámara de la patrulla que ha grabado todo.

Leo el cortometraje, pues, como una representación que denuncia la incapacidad del Estado y de la sociedad por convertir los asesinatos de Juárez en un hecho de memoria. A pesar que desde hace más de veinte años se abrió el primero de los cientos de expedientes no resueltos sobre el tópico, su persistencia como acontecimiento impide inscribirlo dentro de una serie cronológica con una fecha de inicio y una de cierre. Cuando el filme se rodó, los crímenes eran parte ya de los señalamientos del fracaso de las políticas de seguridad ciudadana de los últimos tres sexenios, el de Carlos Salinas de Gortari (19881994), Ernesto Zedillo (1994-2000) y Vicente Fox (2000-2006). Las desapariciones y los asesinatos continuaron en el periodo de Felipe Calderón (2006-2012) y no han cesado con el retorno del Partido Revolucionario Institucional al poder, en la figura de Enrique Peña Nieto (2012-2018). ${ }^{3}$ El pasado continúa experimentándose como presente y de ahí la dificultad de afrontarlo desde una condición de "verdad histórica".

En esta dirección, la obra de Enrique Arroyo trabajaría con una noción diferente del tiempo pasado desde la idea de su finitud y clausura. Su formulación sería cercana a la noción del pretérito perfecto ("han desaparecido", "han masacrado", "han asesinado") tanto por su durabilidad como por la insinuación (contenida en el mismo tiempo gramatical) de su repetición inminente. ${ }^{4}$ El cortometraje, presentado en la pantalla y leído desde su enunciación en un tiempo presente debido al contexto de los hechos, es interpretado por la audiencia desde ese pretérito perfecto que alcanza al presente de la

3 En 2013 persistían los reclamos de los allegados de las víctimas. Éstos documentaban la desaparición de seis jóvenes de entre 12 y 25 años en Juárez y alegaban que: "continúan los feminicidios, las desapariciones de mujeres y la impunidad" (Ballinas 18).

4 El pretérito indefinido ("desaparecieron", "masacraron", "asesinaron") expresa "lo pasajero, en oposición con el sentido durativo del pretérito imperfecto". Pretérito indefinido y presente no se tocan, mientras que el pretérito perfecto podría graficarse con "una flecha cuyo origen se desconoce y cuyo final está claramente dentro del presente" (Seco 73-74).

Revista Iberoamericana, Vol. LXXXI, Núm. 251, Abril-Junio 2015, 569-581 ISSN 0034-9631 (Impreso)

ISSN 2154-4794 (Electrónico) 
proyección, en una malhadada suerte de cohesión temporal. Diseñado para alimentar la ilusión de que los horrores de los cuales somos testigos están ocurriendo delante de nosotros, El otro sueño americano subraya la advertencia realizada por André Guadreault y Francois Jost acerca de la temporalidad cinematográfica: la "cosa filmada" es una acción que "ha sido" mientras que la recepción fílmica "[...] estaría en presente porque nos daría la sensación de que, con todo, sigue la acción "en directo"" (110). El filme omite especificar el tiempo crónico (no hay ninguna indicación sobre en qué año está sucediendo lo que se ve en la pantalla como tampoco señalamientos de si hay breves lapsos omitidos o sobre la duración de lo representado) y sólo en los créditos finales se introduce de manera pronunciada esta marca temporal: "[...] mujeres todas han sido víctimas de la impunidad desde hace 10 años. La PGR reporta 258 muertas hasta agosto de 2003 [...]".

La advertencia en la diégesis del texto sobre cuándo están ocurriendo las acciones es elidida, entonces, en el discurso de los personajes o a través de imágenes explícitas. Sin embargo, se vale de lo que Martine Joly llama "la tentación icónica", mediante la cual se le facilita al espectador el reconocimiento de los objetos del mundo al poner en juego analogías perceptivas: "Debido a que la imagen estimula en el espectador una percepción próxima de aquella que tiene de la realidad, confunde esta analogía con una conformidad entre la imagen y el mundo y espera, entonces, que ella [la imagen] le proponga figuras próximas a aquéllas que él percibe en el mundo mismo" (132-133; traducción mía). Arroyo recurre a señales que van construyendo una posmemoria dado que los hechos traumáticos que siguen ocurriendo en las fronteras norte y sur de México (pero que se han extendido a otras regiones del país) ni pueden remitirse todavía a un pasado, a un ciclo histórico concluido ni hay una certeza de que existan en sus repercusiones emocionales para el grueso del público. La constancia de noticias transmitidas sobre las víctimas de Ciudad Juárez a lo largo de más de veinte años no implica la constitución de un relato ni el que forme parte de la memoria colectiva, por lo que el filme de Arroyo tiende a redundar en ciertos referentes que culturalmente se han asentado en las narrativas sobre estos crímenes con el propósito de obrar en favor de la integración de una narrativa que pueda ser compartida comunitariamente. Se erigiría así tanto en un producto cultural susceptible de ser problematizado dentro de los estudios de la memoria y la posmemoria como en un registro que contribuiría a fijar los marcos sociales que hacen posible que un recuerdo individual se convierta en parte de la memoria social (Halbwachs 41-43).

El cortometraje exhibe un puñado de elementos sobrecodificados desde su nivel icónico, pero insertos en el relato en momentos que permiten ir más allá de su reiteración informativa. Por ejemplo, la audiencia no sabrá quién está reteniendo a Sandra en el vehículo hasta casi el minuto cuatro del filme, cuando ella intenta escapar. En ese instante aparece por primera vez a cuadro (ocupado por la joven durante todo

Revista Iberoamericana, Vol. LXXXI, Núm. 251, Abril-Junio 2015, 569-581 ISSN 0034-9631 (Impreso) 
el tiempo anterior), el segundo personaje, el de la voz masculina que ha predominado en el diálogo escuchado. El pantalón con la cenefa más clara, la gorra, el color verde del uniforme, las esposas que porta remiten a la figura de un agente de policía que, debido a un dato deslizado poco antes ("no quieres verte en la Procu, ¿verdad?"), es posible ubicarlo dentro de un cuerpo determinado, el de la Procuraduría General de Justicia (PGR), máximo órgano del Poder Ejecutivo que se encarga de investigar y perseguir los delitos del orden federal. El reconocimiento del oficio de este personaje y sus acciones (chantajea, humilla, corrompe, golpea salvajemente) contrastan con lo que se esperaría de un agente del orden público. Si bien esto se enlaza con un saber propagado (la corrupción de la policía mexicana) inicia su desplazamiento, al mismo tiempo, a otro ámbito de sentido: el que vincula los acontecimientos de Ciudad Juárez con las instituciones públicas. Ya no sólo por su ineficacia en la solución de los casos criminales y la prevención de los mismos sino en la hipótesis de que sus miembros forman parte de la red que los provoca.

Una segunda forma en que Arroyo propicia el re-conocimiento del tópico tratado es retomando una imagen asumida como parte de los signos vinculados con las muertas de Juárez. Me detendré en una de ellas, la de las cruces floridas o pintadas de color rosa aunque podría haber escogido las vías del ferrocarril, los puentes (cuya significación se ha multiplicado con los colgados y las narcomantas de los años recientes) o el desierto, por mencionar otras igualmente sobresalientes. En El otro sueño americano se hace eco de uno de los íconos más recurrentes y con una alta carga significativa en relación con las jóvenes asesinadas. Recurso primero de los familiares para que la inmensidad y la soledad del desierto llevara la marca de que ahí fueron encontrados cuerpos torturados y sin vida, pronto se extendió a otros enclaves significativos de Ciudad Juárez tanto en los postes pintados de rosa, en las cruces clavadas en ellos o a la vera de las calles.

Ya con la categoría de símbolo, las cruces aparecen en fechas relevantes (como el Día de Muertos, el primero de noviembre) en ubicaciones alejadas, pero relacionadas como lo es Los Ángeles (Los_Angeles_Day_of_the_Dead_Crosses_for_Juarez). Ante la indiferencia, incompetencia, contubernio u olvido de las instituciones del Estado, los familiares y las organizaciones que los han apoyado transformaron esos pedazos de madera tintados en restos de memoria y los sitios en donde los colocaron, en lugares de la memoria, en el mismo tenor con que acuñó el término Pierre Nora. ${ }^{5}$ Estos símbolos comenzaron a aparecer en la filmografía sobre los hechos desde el largometraje pionero de Lourdes Portillo, Señorita Extraviada (1999), en el cual se articulan en forma sobresaliente como mecanismos de resistencia frente al olvido y a los agentes del mismo. A partir de este documental, se han incluido emblemáticamente en otros como el de Alejandra

Aunque se ha impuesto la noción de sitios como algo concreto ("matériels et monumentaux") se piensa también en tópicos y tratamientos, como parte del concepto (Nora 11-12).

Revista Iberoamericana, Vol. LXXXI, Núm. 251, Abril-Junio 2015, 569-581 ISSN 0034-9631 (Impreso)

ISSN 2154-4794 (Electrónico) 
Sánchez, Ni una más (2002), en donde se exhiben desde el segundo de sus catorce minutos de duración, y que luego reciclará como imágenes en su largometraje Bajo Juárez (Sánchez y Juan Antonio Cordero, 2006). Otro de los documentales precursores, Juárez: desierto de esperanza (Cristina Michaus, 2002), subraya la presencia de las cruces mediante la superposición, las cortinillas y la aceleración del metraje que insiste en los postes de luz con la adscripción "ni una más".

Las cruces figurarán en otros títulos posteriores al de Arroyo: en Preguntas sin respuestas (Rafael Montero, 2005), Border Echoes (Lorena Méndez-Quiroga, 2006), Juárez: the City Where Women are Disposable (Alex Flores, 2007). Y también en largometrajes de ficción: Las muertas de Juárez (Enrique Murillo, 2002), Bordertown (Gregory Nava, 2007) y Backyard. El traspatio (Carlos Carrera, 2009), entre otros. Por lo tanto, El otro sueño americano actúa como un eslabón temprano de una ya larga cadena de productos audiovisuales que proponen estos artefactos como detonadores de una memoria que aspira, así, a formularse como colectiva. En su explicación sobre cómo los sujetos reconstruyen las lecturas de su infancia, Halbwachs apunta la selectividad del proceso en cuanto a que éste se genera a partir de las partes del todo: unos cuantos rasgos, descripciones, indicaciones, proposiciones "[...] que progresivamente inscriben una figura o un paisaje en la mente del lector, los cuales le permiten penetrar en el corazón del recuerdo" (46; mi traducción). Las imágenes de las cruces clavadas en espacios abiertos y públicos a la vista de todos se desempeñan como elementos que a fuerza de su reiteración visual pueden transitar desde el nuevo valor referencial con el que han sido investidas hasta su nueva carga simbólica.

En el cortometraje que analizo, esas señales destinadas a evocar a los muertos guardan en la recomendación de Genaro a Timoteo, su correlato: "Y dice el 'boss' que ya no las tires por las vías. Ya se la saben". La exhibición de las cruces no ocupa más que unos cinco segundos en la pantalla. La audiencia apenas reparará en ellas en razón de la composición del plano y las decisiones de cómo se presentará el contexto referencial de la historia relacionado con el espacio exterior de la patrulla. Mientras que en el interior del vehículo se insinúa por el diálogo la escena de sexo oral ya descrita, la ventanilla levantada también la sugiere a través del reflejo. La escena va preparando al espectador al espectáculo de horror constituido por el filme, pues articula el fuera de campo del primer plano (la felación) con el cuadro en midground en el que aparecen las cruces. La simultaneidad de lo que no se ve pero se comprende en virtud del sonido ("Despacio, despacio, así, despacio... Ahhh...así es, despacio... Agghhh") y la disposición del cuerpo femenino entrevisto por el cristal se complementa con lo que se ve con claridad (las cruces) y se escucha (el silbido del tren). Si Sandra se prostituye en estos momentos es porque piensa que así va a ser liberada; ése es el pacto inicial entre ellos, explicitado en la historia. Sin embargo, el relato lo desmiente de antemano al introducir la referencialidad de las cruces mientras ocurre la felación. Arroyo fuerza

Revista Iberoamericana, Vol. LXXXI, Núm. 251, Abril-Junio 2015, 569-581 ISSN 0034-9631 (Impreso) 
así al espectador a integrar el cortometraje en un discurso más amplio al del infortunio de la joven de la trama y sitúa al texto artístico dentro de un marco de referencia de carácter social y político.

El tercer elemento de naturaleza icónica que ha sido codificado y con el cual cerraré este apartado, es la imagen de la camiseta que porta Timoteo. Se trata de la fotografía de John Lennon que ilustró la portada del disco Imagine. En esta ocasión, el correlato se establece de inmediato con el rechazo de Genaro ante el ofrecimiento del estadounidense que le extiende un carrujo: “Esa es droga de soldado, Timoteo, ¿qué pasó?” El resorte memorístico se dispara al enlazar el himno de Lennon, punta de lanza del álbum del cantante de 1971 y la guerra de Vietnam. Si la canción reza "Nothing to kill or die for $[\ldots]$ No need for greed or hunger" y con ello da pie para que quien se apropie del discurso sea un soñador dueño de una utopía posible, el texto cinematográfico afirma exactamente lo contrario. Arroyo remite a Vietnam y al uso extendido de la droga que no fue restringido por el gobierno de Estados Unidos sino hasta varios años después de iniciado el conflicto bélico. De esta forma, invoca al papel consumidor de ese país y al rol proveedor de algunas naciones latinoamericanas. La inclusión de la imagen de Lennon en la prenda de vestir de Timoteo aparejada a su consumo de mariguana resitúa de nuevo al cortometraje en un contexto de alcances mayores. No sólo desde una perspectiva histórica, también en el ámbito de las relaciones entre Estados Unidos y México. Por una parte, alude a la amplitud de las transacciones delincuenciales que no se limitan a las drogas blandas ni tampoco a las duras sino que alcanza la comercialización de seres humanos (tráfico sexual y de personas para ser objeto de diversiones perversas y mortales, o venta de órganos). Así, la trata de personas estaría anudada a otras aristas del crimen organizado. ${ }^{6}$ Por otro lado, invita a reparar sobre cómo determinados productos de la cultura popular se han vaciado -por lo menos parcialmente- de significado y se han llenado de otros, como es el caso de la imagen y la canción de Lennon. La invitación a un mundo sin fronteras ("imagine there's no countries") presenta una lectura irónica porque, en efecto, las barreras se han disuelto en las transacciones desde una perspectiva global. Y en este sentido, los objetos de consumo circulan sin reconocer los límites nacionales, a diferencia de lo acontecido con Sandra. Para los pobres y los inmigrantes (sustantivos que no necesariamente se traslapan) los lindes son infranqueables, mortales incluso y unidireccionales. La imagen es irónica porque frente al brotherhood of man del artista, Arroyo ubica en este segmento las mayores apelaciones al horror, a través de los golpes propinados a la chica, la descripción del dolor futuro y el fin que le espera, al igual que la tensa relación entre Timoteo y Genaro, alegoría de las existentes entre Estados Unidos y México.

6 Tal vínculo se da por sentado desde los instantes iniciales del cortometraje, cuando la audiencia comprende que la joven es hecha prisionera por prostitución pero también por posesión de cocaína.

Revista Iberoamericana, Vol. LXXXI, Núm. 251, Abril-Junio 2015, 569-581 ISSN 0034-9631 (Impreso)

ISSN 2154-4794 (Electrónico) 


\section{LA ESTRUCTURA TEMPORAL Y TEMÁTICA}

Arroyo opta por manejar el tiempo de la historia de una forma muy cercana a nuestra comprensión del tiempo real. Las categorías desarrolladas por Gérard Genette sobre el orden, la duración y la frecuencia son fusionadas en este filme, tanto en el nivel del relato como en el de la diégesis. Así, lo narrado coincide con la narración; aunque el tiempo de la historia es evidentemente más largo que el de la enunciación, el cortometraje introduce dos elipsis imperceptibles justificadas por los cortes intermitentes de la grabación registrada por la cámara instalada en la patrulla del policía. Por ejemplo, el segmento del sexo oral, el intento de escape de la joven, los golpes, el trayecto hacia la guarida de Timoteo ocuparían en la vida real un lapso mayor a los diez minutos de duración del cortometraje. Al introducir una explicación diegética tendiente a invisibilizar la elipsis, se transmite la ilusión de que el espectador está presenciando una escena, la cual iguala el tiempo del relato con el tiempo de la historia. El filme perseguiría ofrecer "un todo espacio-temporal" sin fisura alguna entre ambos niveles en un deseo de desarrollar, en términos de Christian Metz, "una escena de la vida corriente" (Guadreault 127). Y, finalmente, el número de acciones que corresponden a la diégesis se corresponden puntualmente con el número de veces en que son contadas.

Las decisiones adoptadas en cuanto al planteamiento de la temporalidad se refuerzan con elementos propios de la puesta en escena. El punto de vista elegido propiciaría una sensación parecida al de los programas de televisión en los que la audiencia ve qué ocurre con personajes reales que, por ejemplo, se suben a un taxi y así conocen los peligros de la vida nocturna de las grandes ciudades o aquellos que los incitan a vivir (sin riesgos) la experiencia de servidores públicos en situaciones de emergencia (policías, bomberos, escuadrones médicos o del orden, etcétera). La técnica de la cámara oculta para captar in fraganti sucesos inesperados azuza la curiosidad de los espectadores y sus inquietudes voyeuristas.

Un par de ejemplos destacados me permitirá ilustrar la naturaleza de los espectáculos emulados formalmente por este cortometraje. El primero de ellos es America's Most Wanted, el cual tuvo una vida de casi un cuarto de siglo en las pantallas estadounidenses y latinoamericanas (1988-2012). Mediante el despliegue de casos relevantes vinculados con perseguidos por la ley, su presentador remataba cada capítulo con una frase como ésta: "And remember, you can make a difference", con lo cual se motivaba al público a participar en la captura de delincuentes, en la búsqueda de personas desaparecidas y aportar información que permitiera cerrar casos no resueltos por las instituciones correspondientes. El segundo es el programa Unsolved Misteries que se mantuvo al aire en un periodo similar al de America's Most Wanted (1987-2002). El sitio oficial del primero asienta: "Misterios reales y crímenes son simulados y detallados a fin de generar información útil para resolverlos. Incluye archivos de casos investigados" (Life

Revista Iberoamericana, Vol. LXXXI, Núm. 251, Abril-Junio 2015, 569-581 ISSN 0034-9631 (Impreso) 
Time Networks, mi traducción). El otro sueño americano retomaría varias líneas de estos títulos: los recursos formales como el reenacment o actuación que repite un hecho real; la temática delictiva no concluida o no sancionada aún legalmente; la solicitud de involucramiento de la audiencia y que en el texto de Arroyo estaría remarcada con la

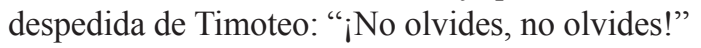

Gracias al plano fijo (la cámara no se mueve en ningún momento) se transmite la idea de que no existe manipulación alguna, debido a que el público ve lo que está ahí, sin que nadie -aparentemente- focalice por él (no varía la escala de planos, tampoco se presentan encuadres de un personaje a otro o cambios de foco que lo centren en un fore, un mid o un background, por ejemplo). Se evoca el tipo de producción de la telerealidad como en The Osbournes: "[...] cámaras colocadas de tal modo que mostraran todo el espacio escénico donde sucedían los acontecimientos; sin embargo, existe una carencia intencionada de alardes técnicos, grúas, travelings y panorámicas, centrando su tono espectacular, no en la belleza de sus imágenes, sino en los comportamientos de los concursantes" (Perales Bazo 123). Tal carencia de alardes alimenta la sensación de estar testimoniando (o incluso participando) en la realidad de las situaciones planteadas. Al eliminar una peculiaridad de los reality, el que son el resultado de una producción (se escoge lo mejor de la semana, se sintetiza lo ocurrido durante el día, se editan las actividades desarrolladas) y se propone una suerte de episodio "en directo". El otro sueño americano reafirma su cercanía con lo real y aviva el sentido voyerista de los receptores.

Así, si el estilo del filme favorece el involucramiento intelectual y emocional del espectador, la manera como se propone la historia va generando cuestionamientos sobre el tipo de producto audiovisual que se tiene ante sí. En un inicio no es evidente ni quién cuenta la historia ni cómo se ha obtenido. La identificación de quién es uno de los dos primeros interlocutores, según he apuntado antes, no aparece sino hasta avanzado el corto y es evidente sólo cuando la iconicidad del uniforme del policía es revestida de referencialidad (mediante el reconocimiento de las características del uniforme, los dispositivos utilizados, las actitudes y comportamientos). De aquí que, posiblemente, la audiencia pase por alto el primer momento en donde se establece la identidad del agente del orden y la colija después, en el diálogo con Timoteo, o incluso hasta el momento final, cuando por primera y última vez su rostro es captado de frente por la cámara de la patrulla. En ese preciso instante, incluso, se aclara mediante qué aparato de grabación se ha captado aquello presenciado por los receptores.

El objetivo del tratamiento visual y auditivo de este texto cinematográfico es que el realismo sea tal, que parte del horror provocado proviene de la posibilidad de que el material no sea una ficción sino un footage, una cinta real, encontrada y exhibida. Esto se descarta de manera definitiva en el cierre del filme, heterodiegéticamente, mediante el paratexto que comienza así: "Sería grato decir que alguna semejanza con la realidad, es mera coincidencia. Ciertamente, nuestros personajes son ficticios, pero no es ficción

Revista Iberoamericana, Vol. LXXXI, Núm. 251, Abril-Junio 2015, 569-581 ISSN 0034-9631 (Impreso)

ISSN 2154-4794 (Electrónico) 
que niñas de 11 años, estudiantes, amas de casa, prostitutas, obreras, mujeres todas, han sido víctimas de la impunidad desde hace diez años". Pero antes de llegar a este punto, se opta por una serie de procedimientos técnicos ejercidos sobre la imagen y el sonido similares a la de los videos caseros, los materiales de archivo y los incluidos en los programas televisivos mencionados sobre casos delictivos no resueltos. Por ejemplo, la calidad de la imagen es degradada a fin de aumentar la impresión de realidad originada en la imperfección de equipos de filmación improvisados o de bajo costo. Para conseguirlo, la fotografía se sobrexpuso y de ahí la diferencia entre la apariencia del interior del vehículo y el exterior del mismo. Los paisajes y el contexto vistos fuera de la patrulla y captados fugazmente debido al movimiento de ésta, parecerían diluirse ante el aspecto sólido y contundente de lo que ocurre dentro de ella.

Tales procedimientos corren a la par de los rasgos habituales de la narrativa realista: una fidelidad, en general, al tiempo cronológico como un principio ordenador; una voz narrativa organizadora; una estructura tradicional dotada de inicio, desarrollo y conclusión, y organizada para llegar a un desenlace; la aportación de fechas e información de alto contenido referencial; y la ilusión de una autenticidad histórica (Berzani 49-51). Lo que está ante la mirada espectatorial es indudable tal y como se asumen los reality-shows (o por lo menos, con los primeros ejemplos de esta índole) tanto por las elecciones técnicas como por las características de realidad exhibidas por lo narrado. Los casi nulos indicios que induzcan a la basculación interpretativa acerca de la objetividad y estatus de realidad del relato nutren la incertidumbre y la ansiedad de los lectores de este texto audiovisual. Ello, debido a que usualmente estos productos satisfacen la sed de categorías y de distinciones significativas de cualquier espectador (por ejemplo, certezas que permiten determinar su condición documental o ficticia, el género cinematográfico, su origen industrial o casero).

Sin embargo, el material proyectado desazona justamente porque descoloca una idea largamente asumida a partir de los estudios de Michel Foucault: la omnipresencia de la cámara (la imposibilidad de escapar a su ojo vigilante) regula los comportamientos y propicia la autocensura cuando se presiente la violación de la norma; su registro se transforma en una prueba susceptible de generar una sanción. En El otro sueño americano, el panóptico pierde cualquier eficacia al poder ser manipulado según el antojo de quien supuestamente debería ser el vigilado. Ese "supuestamente" se encamina a ocasionar la inquietud de la audiencia dado que el representante del orden y la cámara tendrían un propósito similar: actuar como agentes que favorezcan el respeto de las leyes con objetividad. De ahí que el ojo del dispositivo no esté dirigido al policía sino a la zona adjudicada a los probables delincuentes. En el momento en el que se pierden los límites entre la autoridad y el sujeto criminal, y en el que la objetividad del registro deja de tener sentido, merman las convicciones alrededor de los discursos y las estructuras de verdad.

$\mathrm{Ni}$ los antecedentes de la protagonista ni los oficios del personaje masculino se ofrecen de manera directa sino que deben ser colegidos, interpretados y asociados para 
que una vez finalizado el texto cinematográfico, la audiencia intente encontrar una coherencia imposible a pesar de que la historia sí se cierra. Es decir, intradiegéticamente, El otro sueño americano cuenta una anécdota preparada para horrorizar al receptor en forma creciente en tres tiempos: el pretérito que aporta los antecedentes de la situación, el presente al cual se le dedica gran parte de lo escenificado y el futuro que (como en el caso del primer segmento) se prevé a partir del diálogo. Pero dado que el discurso del relato coincide acumulativamente con el discurso circulante en la realidad, en el nivel extradiegético la historia es propuesta como un segmento in media res; es contado como un acontecimiento generado por muchos otros marcados por la violencia sin límites (la pobreza, la prostitución, la debilidad de un sistema educativo, judicial, legislativo y ejecutor, la existencia de un mercado global cuyos bienes de consumo deben de abastecerse a cualquier costa). Por lo tanto, se propone a la manera de un continuum no lineal, desde el cual pueden configurarse otras situaciones igualmente violentas (secuestro de niños, tráfico de órganos) en un presente sostenido. El tino de tal estructura narrativa es la eficacia en la reactualización de su lectura, a pesar de que ha transcurrido casi una década desde su estreno. Pero tal acierto forma parte del horror que provoca, puesto que la audiencia desearía leerlo en pasado, como un momento histórico de pesadilla que pudo dejarse atrás. Y no es así. La angulación fija y la inmovilidad del plano, elegidas para sostenerse durante todo el metraje, remiten de manera obvia al dispositivo que está grabando lo que ocurre (la cámara instalada en el interior de la patrulla). Al mismo tiempo, funcionan como constantes de una realidad siempre presente que pareciera inconmovible, inmóvil, no susceptible de ser transformada.

He articulado de manera simple los tres tiempos formulados en las siete tomas del texto (hábilmente suturadas en la posproducción): el primero, un pasado que se condensa en los antecedentes que propician la comprensión de por qué la chica llegó a la frontera; el segundo, un presente sobre el cual se ensambla la historia presentada; y el tercero, un futuro cierto en su desaliento y en formas múltiples de violencia extrema, previsto desde un presente sostenido. Es un futuro que es ya un presente o un presente que contiene en sí mismo un futuro. En este sentido, la sencillez de la estructura del relato (al desarrollarse en forma lineal y cronológica para así coincidir con la estructura de la historia) está planeada para romper la perspectiva tradicional de la concepción del tiempo y profundizar en el horror del desenlace. Si la conclusión del filme no prevé ningún cambio y el presente es tremendamente perturbador, el espectador es despojado de cualquier asidero de bienestar emocional. Para ello, Arroyo procura eliminar cualquier ángulo que pudiera agobiar visual, auditiva o cognitivamente a la audiencia, a fin de que ésta pueda encauzar su atención y su involucramiento emocional en la relación entre Sandra y el policía durante las dos terceras partes del cortometraje, y entre Genaro y Timoteo, después.

En una entrevista concedida por el director del filme, al explicar el proceso que lo condujo a la escritura del guión reveló que desde varios años atrás había ido acopiando

Revista Iberoamericana, Vol. LXXXI, Núm. 251, Abril-Junio 2015, 569-581 ISSN 0034-9631 (Impreso)

ISSN 2154-4794 (Electrónico) 
recortes de periódicos sobre las mujeres desaparecidas y asesinadas en Ciudad Juárez. Entre 1995 y el inicio del rodaje, casi una década más tarde, el realizador pudo madurar la anécdota que deseaba desarrollar y la manera que pensó sería la más eficaz para contarla ("El otro sueño"). De aquí que el desenlace aglutine hallazgos que fueron estremeciendo a lo largo del tiempo a la opinión pública: cuerpos con pezones y genitales mutilados, quemados parcial o totalmente, con las vísceras estalladas. La materia inerte encontrada es testimonio del ser vivo sobre el cual se llevaron a cabo todo tipo de perversiones encaminadas a generar umbrales máximos de dolor.

Este último segmento del filme sitúa al feminicidio masivo de Juárez dentro de una problemática que rebasa el interés local, de quienes se preocupan por las violaciones en función del género o el espectro de los Derechos Humanos y refuerza las preguntas sobre si sería pertinente hablar de genocidio. Si estos ámbitos ya son de por sí un tema que nos concierne debido a sus repercusiones pragmáticas y a su relevancia por los impactos éticos que conllevan, la formulación del filme obraría en favor de la generación de experiencias hipermediadas, en la línea de las propuestas de James Young (Szurmuk 225). Si “[...] la discusión sobre la memoria raras veces puede ser hecha desde afuera, sin comprometer a quien la hace, sin incorporar la subjetividad del/a investigador/a [...]" (Jelin 3), El otro sueño americano fuerza a la audiencia a transformar la objetividad de la cámara que graba en el punto de vista subjetivo de quien mira lo que está siendo filmado. El papel voyerista del espectador alcanza cotas de alta productividad al conferirle una función de testigo, convocado a dar cuenta de lo acontecido a raíz de la interpelación con que cierra el cortometraje: "No olvides, no olvides".

\section{BiBLIOGRAFÍA}

Ballinas, Víctor. “Continúan los feminicidios en Ciudad Juárez”. La Jornada. 11 marzo 2013. <www.jornada.unam.mx/2013/03/11/politica/018nlpol>. Octubre 2013.

Berzani, Leo. "Le Réalisme et la peur du désir". Littérature et réalité. Gérard Genette y Tzvetan Torodov, eds. Paris: Éditions du Seuil, 1982. 46-80.

El otro sueño americano. Enrique Arroyo, dir. El Séptimo Sello Pilse, IMCINE, 2004.

"El otro sueño americano: entrevista". 6 mayo 2008. <http://www.youtube.com/

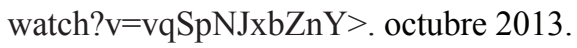

Foucault, Michel. Vigilar y castigar. El nacimiento de la prisión. México: Siglo XXI editores, 1976.

Gaudreault, André y Francoist Jost. El relato cinematográfico. Cine y narratología. Barcelona: Paidós, 1995.

Genette, Gérard. Figuras III. Barcelona: Lumen, 1989.

Halbwachs, Maurice. On Collective Memory. Chicago: The U of Chicago P, 1992.

Jelin, Elizabeth. Los trabajos de la memoria. Buenos Aires: Siglo XXI Editores, 2002.

Revista Iberoamericana, Vol. LXXXI, Núm. 251, Abril-Junio 2015, 569-581 
Joly, Martine. L'image et les signes. Approche sémiologique de l'image fixe. París: Nathan, 2000.

Life Time Networks. “About”. Unsolved Mysteries.20 nov. 2013. <http://www.unsolved. com>. Octubre 2013.

Nora, Pierre. "Comment écrire l'histoire de France?". Les Lieux de mémoire, Vol. 3 - Legacies. Pierre Nora y David P. Jordan, eds. Paris: Gallimard, 1992. 11-30.

Perales Bazo, Francisco. “La realidad mediatizada: el reality show". Revista Comunicación 1/9 (2011): 120-131.

Seco, Rafael. Manual de gramática española. Madrid: Aguilar, 1978.

Szurmuk, Mónica. "Posmemoria". Diccionario de estudios culturales latinoamericanos. México: Siglo XXI, Instituto Mora, 2009. 224-228.

Univisión. "Polémica canción sobre muertas de Juárez". Univisión Noticias. 2004. $<$ http://foro.univision.com/t5/Ciudad-Juarez/LAS-MUERTAS-DE-JUAREZcancion-polemica/td-p/135/0275> Junio 2013.

Valdata, Marcela. "Memoria". Diccionario de estudios culturales latinoamericanos. México: Siglo XXI-Instituto Mora, 2009. 173-176. 
